Article

\title{
Programmable Thermal Dissociation of Reactive Gaseous Mercury, a Potential Approach to Chemical Speciation: Results from a Field Study ${ }^{\S}$
}

\author{
Cheryl Tatum Ernest ${ }^{1, \dagger}$, Deanna Donohoue ${ }^{1, \ddagger}$, Dieter Bauer ${ }^{1}$, Arnout Ter Schure ${ }^{2}$ and \\ Anthony J. Hynes 1,*
}

1 Division of Marine and Atmospheric Chemistry, Rosenstiel School of Marine and Atmospheric Science, University of Miami, 4600 Rickenbacker Causeway, Miami, FL 33149, USA;

E-Mails: cheryl.ernest@mpic.de (C.T.E.); deanna.1.donohoue@lawrence.edu (D.D.); dbauer@rsmas.miami.edu (D.B.)

2 Electric Power Research Institute, 3420 Hillview Avenue, Palo Alto, CA 94304, USA;

E-Mail: aterschu@epri.com

$\dagger$ Current Address: Atmospheric Chemistry Department, Max Planck Institute for Chemistry, Hahn-Meitner-Weg 1, D-55128 Mainz, Germany.

* Current Address: Department of Chemistry, Lawrence University, Appleton, WI 54911, USA.

$\S$ Based on "Tatum Ernest, C.; Donohoue, D.; Bauer, D.; Ter Schure, A.; Hynes, A.J. Programmable thermal dissociation of reactive gaseous mercury-A potential approach to chemical speciation: Results from a field study. Atmos. Chem. Phys. Discuss. 2012, 12, 33291-33322”.

* Author to whom correspondence should be addressed; E-Mail: ahynes@rsmas.miami.edu; Tel.: +1-305-421-4173; Fax: +1-305-421-4689.

Received: 9 May 2014; in revised form: 17 July 2014 / Accepted: 22 July 2014 / Published: 13 August 2014

\begin{abstract}
Programmable Thermal Dissociation (PTD) has been used to investigate the chemical speciation of Reactive Gaseous Mercury ( $\mathrm{RGM}, \mathrm{Hg}^{2+}$ ). $\mathrm{RGM}$ was collected on denuders and analyzed using PTD. The technique was tested in a field campaign at a coal-fired power plant in Pensacola, Florida. Stack gas samples were collected from ducts located after the electrostatic precipitator and prior to entering the stack. An airship was used to sample from the stack plume, downwind of the stack exit. The PTD profiles from these samples were compared with PTD profiles of $\mathrm{HgCl}_{2}$. Comparison of stack and in-plume samples suggest that the chemical speciation are the same and that it is possible
\end{abstract}


to track a specific chemical form of RGM from the stack and follow its evolution in the stack plume. Comparison of the measured plume RGM with the amount calculated from in-stack measurements and the measured plume dilution suggest that the stack and plume RGM concentrations are consistent with dilution. The PTD profiles of the stack and plume samples are consistent with $\mathrm{HgCl}_{2}$ being the chemical form of the sampled RGM. Comparison with literature PTD profiles of reference mercury compounds suggests no other likely candidates for the speciation of RGM.

Keywords: programmable thermal dissociation; mercury; gaseous elemental mercury; reactive gaseous mercury

\section{Introduction}

The specific chemical speciation of mercury in flue gas emitted from coal-fired power plants (CFPPs) has important implications for its impact on the environment. The rate of wet and dry deposition and any potential atmospheric reactivity will depend both on the oxidation state of mercury and also on the specific chemical form of any oxidized mercury. The importance of understanding chemical speciation has been highlighted by work that suggests that oxidized mercury may be reduced to elemental mercury in power plant plumes.

The first observations of in-plume reduction were reported by Edgerton et al. [1] who measured Gaseous Elemental Mercury (GEM, $\mathrm{Hg}^{\circ}$ ), Reactive Gaseous Mercury ( $\mathrm{RGM}, \mathrm{Hg}^{2+}$ ) and fine particulate mercury (Hg-P) at three sites in the southeastern United States (U.S.), using simultaneous measurements of $\mathrm{SO}_{2}$ and $\mathrm{NO}_{\mathrm{y}}$ to identify plumes from CFPPs. Their measurements suggested that total-Hg (i.e., GEM + RGM) was essentially conserved from the point of emission to the sampling site; however, GEM was the dominant component with less than $20 \%$ present as RGM. This contrasted strongly with speciation estimates obtained from EPRI-ICR model equations for CFPPs that burn bituminous coal. The EPRI-ICR model [2] is an empirical correlation model developed with ICR (EPA Information Collection Rule) coal analysis data and stack test data and it predicted that RGM should be the dominant component of the total mercury in the observed plumes.

Lohman et al. [3] simulated nine power plant plume events with a reactive plume model that included a comprehensive treatment of plume dispersion, transformation, and deposition. Their study focused on observations at one of the sites, Yorkville, GA, USA, used in the Edgerton et al. [1] study. The EPRI-ICR model was used to predict the speciation of the mercury emitted from the CFPP's in the vicinity of the Yorkville site. The reactive plume model was then used to examine any change in the speciation of mercury as a result of in-plume chemistry. The model simulations failed to reproduce any depletion in RGM that could rationalize the observations of Edgerton et al. [1] and, as possible explanations they modeled RGM reduction to GEM in the plume by unknown chemistry, rapid reduction of RGM on ground surfaces, and/or an overestimation of the RGM fraction in the power plant emissions by the EPRI-ICR model. The incorporation of either a pseudo-first order decomposition of RGM or reaction with $\mathrm{SO}_{2}$ as possible in-plume reduction processes produced better agreement with the observations. 
Deeds et al. [4] reported on an aircraft study of mercury speciation in a CFPP plume at the Nanticoke generating station in Ontario, Canada. They found that the speciation in the plume was significantly different than the estimated stack speciation. Although they concluded that both elemental and particulate mercury levels were consistent with plume dilution, they did not observe a mass balance in total mercury and they saw significantly lower levels of RGM than would have been expected based simply on plume dilution alone. In contrast, a study carried out at the We Energies Pleasant Prairie Power Plant, Pleasant Prairie, Wisconsin, utilized aircraft and ground measurements and concluded that there was significant reduction in the fraction of Reactive Gaseous Mercury (RGM) (with a corresponding increase in the fraction of elemental mercury) as part of the Total Gaseous Mercury (TGM) emitted from the Pleasant Prairie stack [5]. Both studies demonstrate the difficulties of obtaining quantitative plume data using aircraft sampling.

In this context, the Electric Power Research Institute (EPRI) and the United States Environmental Protection Agency (USEPA) sponsored a major field campaign at CFPP Crist in Pensacola, Florida [6]. The objectives of the campaign were, by making simultaneous measurements of both GEM and RGM in the boiler stack and in the stack emission plume, to (A) determine if significant reduction of RGM was occurring in the plume; and (B) investigate the rate of reaction if significant reduction was observed. If GEM/RGM ratios in the plume were observed to be significantly higher than those ratios within the stack, then this would be evidence of such conversion occurring. The stack measurements were made using both a mercury continuous emission monitoring system (CEMS) and the Ontario Hydro method to inter-compare methods and provide confidence in the measured stack concentrations. Rather than using an aircraft that would traverse the plume, the Crist campaign utilized an airship as a sampling platform that could maintain the sampling instrumentation within the plume and measure at a variety of distances from the stack to follow the evolution of the plume chemistry. The plume measurements were designed to incorporate both a CEMS system that was identical to the stack system, avoiding instrumental bias, together with manual denuder measurements of RGM. In addition, a variety of ancillary measurements were made both in the stack and plume [6].

The chemistry of mercury in combustion emissions has been reviewed in detail by Schofield [7] who concluded that heterogeneous processes are responsible for mercury oxidation in flue gas, with homogeneous gas phase chemistry playing no role. This explains both the variability in the fraction of total mercury that is oxidized in CFPP and the inability of combustion models to predict this variability. Prior work on the speciation of mercury in CFPP flue gas has attempted to quantitatively measure the concentrations of GEM and total RGM. It is currently assumed that mercuric chloride, $\mathrm{HgCl}_{2}$, is the major component of oxidized mercury in the combustor [7,8], and hence the major component of the oxidized mercury in the exhaust plume. However, to date no direct measurements of $\mathrm{HgCl}_{2}$ in either stack or plume gases have confirmed this. Identification of the specific chemical components of RGM would improve our understanding of the mercury oxidation chemistry within power plant combustion systems and allow us to better understand the fate of RGM after it exits the power plant stack and interacts with the ambient atmosphere. Preliminary studies in our laboratory [9] suggested that collection of RGM on denuders coupled with analysis using programmable thermal dissociation (PTD) could provide information on the specific chemical speciation of RGM. As a result, PTD measurements were included as an innovative component of the Plant Crist campaign, 
but precluding any additional characterization of the PTD approach prior to the field campaign. In this sense, the field measurements were an attempt to characterize the potential of PTD analysis applied to samples collected in a realistic combustion environment. It was in effect a "proof of concept" experiment. The results are, however, of value because of the unique nature of this field experiment, with simultaneous sampling in the stack and the stack plume.

\section{Results and Discussion}

\subsection{Prior PTD Studies}

PTD has been used for the analysis of solids containing mercury compounds. The PTD profiles obtained here can be compared with prior published work on solid $\mathrm{HgCl}_{2}$ samples, and other representative mercury compounds. In comparing it is important to note that the prior studies used much higher concentrations of RGM. Since they used small amounts of a solid sample, the oven temperature distribution was, in contrast to this study, not a problem. In addition, some techniques were designed to be able to distinguish between thermal desorption, i.e., the evaporation or sublimation of the mercury compound, and decomposition to produce GEM. Bister and Scholz [10] used PTD to examine mercury speciation in contaminated soils. They used atomic absorption for detection of GEM. Calibration samples were diluted with quartz powder. To distinguish between desorption and decomposition the vapor passed through an $800{ }^{\circ} \mathrm{C}$ quartz pyrolysis tube before analysis thus measuring the sum of desorption and decomposition. By bypassing the pyrolyzer they could monitor decomposition alone. Their PTD profile of $\mathrm{HgCl}_{2}$ shows decomposition starting at $\sim 80{ }^{\circ} \mathrm{C}$ and peaking at $200{ }^{\circ} \mathrm{C}$. They saw no difference in PTD profiles obtained by bypassing the pyrolyzer and it was concluded that decomposition was occurring exclusively.

Feng et al. [11] used ICPMS detection of GEM, examining aerosol samples collected in Toronto, Canada. The detection technique presumably measured the sum of desorption and decomposition although this was not explicitly discussed. Their calibration samples were diluted using fly ash. For $\mathrm{HgCl}_{2}$ they showed a very broad PTD profile with decomposition/desorption starting at $100{ }^{\circ} \mathrm{C}$ and peaking at $300{ }^{\circ} \mathrm{C}$.

Lopez-Anton et al. [12] used a commercially available thermal dissociation module coupled with a CVAFS detector. They used a pyrolyzer prior to analysis and would have detected both dissociated and desorbed/sublimed RGM. They examined fly ash and solid mercuric compounds generating standards by mixing pure compounds with powdered quartz and obtained a very sharp $\mathrm{HgCl}_{2} \mathrm{PTD}$ profile with appearance at $\sim 70{ }^{\circ} \mathrm{C}$ and the peak at $125^{\circ} \mathrm{C}$.

$\mathrm{Wu}$ et al. [13] used mass spectrometry and this allowed them to simultaneously monitor decomposition, producing GEM, and desorption, monitoring $\mathrm{HgCl}_{2}$ directly. Their standard compounds were diluted with several solid powders. Commercial $\mathrm{SiO}_{2}, \mathrm{TiO}_{2}, \mathrm{Al}_{2} \mathrm{O}_{3}$, and coconut shell $\mathrm{AC}$ were used as diluents and interestingly, both the shape of the PTD profile and the ratio of $\mathrm{GEM}: \mathrm{HgCl}_{2}$ varied dramatically as a function of the diluent powders. For example, using the powdered quartz diluent a broad PTD profile was obtained with a peak at $150{ }^{\circ} \mathrm{C}$ and with GEM and $\mathrm{HgCl}_{2}$ being detected in equal amounts. In contrast, a PTD profile with $\mathrm{Al}_{2} \mathrm{O}_{3}$ diluent was much sharper with a peak at $150{ }^{\circ} \mathrm{C}$ but consisting exclusively of GEM. 
These studies also examined the PTD profiles of other $\mathrm{Hg}(\mathrm{II})$ and $\mathrm{Hg}$ (I) compounds, $\mathrm{HgS}, \mathrm{HgSO}_{4}$, $\mathrm{HgO}, \mathrm{HgBr}_{2}, \mathrm{Hg}_{2} \mathrm{Cl}_{2}$ and $\mathrm{Hg}_{2} \mathrm{SO}_{4}$. In general, the non-halide $\mathrm{Hg}(\mathrm{II})$ compounds are found to dissociate at higher temperatures than $\mathrm{HgCl}_{2}$ although there is considerable variability between the studies. Lopez-Anton et al. [12] show a PTD profile for $\mathrm{HgBr}_{2}$ that has its decomposition peak shifted slightly to lower temperature relative to $\mathrm{HgCl}_{2}$. It is also clear that there is significant variability in the results of these studies.

In addition to using considerably higher mercury concentrations than our work, all of the studies used a linear temperature ramp in contrast to the ramp and hold sequence that was used here. As we note below we have now switched to a linear ramping sequence. Unfortunately, we were not aware of the two prior literature studies [10,11] at the start of the Crist campaign in 2008, hence our decision to use the ramp and hold sequences described as "oven 1" and "oven 2". The "oven 2" sequence is probably closest to a straight ramping sequence and the "oven 2" profiles are similar to published PTD profiles and to our more recent, better defined work shown in Supplemental Figure S1 The "oven 1" profiles show more variability and if the work of Wu et al. [13] is correct this may be due at least in part to the competition between sublimation and decomposition. We plan to modify our implementation of PTD by incorporating a pyrolyzer and second LIF detection cell to be able to simultaneously monitor both dissociation and desorption/sublimation profiles.

\subsection{Laboratory $\mathrm{HgCl}_{2}$ PTD Profiles}

Laboratory PTD profiles of $\mathrm{HgCl}_{2}$ were obtained after the completion of the Crist field experiment using two thermal ramping schemes that we denote as "oven 1" and "oven 2". Figure 1 shows the individual and averaged calibration profiles obtained at a single deposition flow for the "oven 1" thermal cycle. The LIF signal has been normalized by the signal resulting from the injection of known amounts of GEM, as described in Section 3.6.

Figure 1. Six programmable thermal dissociation (PTD) profiles using Oven 1 program for an uncoated tubular denuder loaded with pure $\mathrm{HgCl}_{2}$. Denuders were loaded by flowing $\mathrm{N}_{2}$ over pure $\mathrm{HgCl}_{2}$ for $1 \mathrm{~min}$ at $135 \mathrm{sccm}$. The average of the six profiles is also shown.

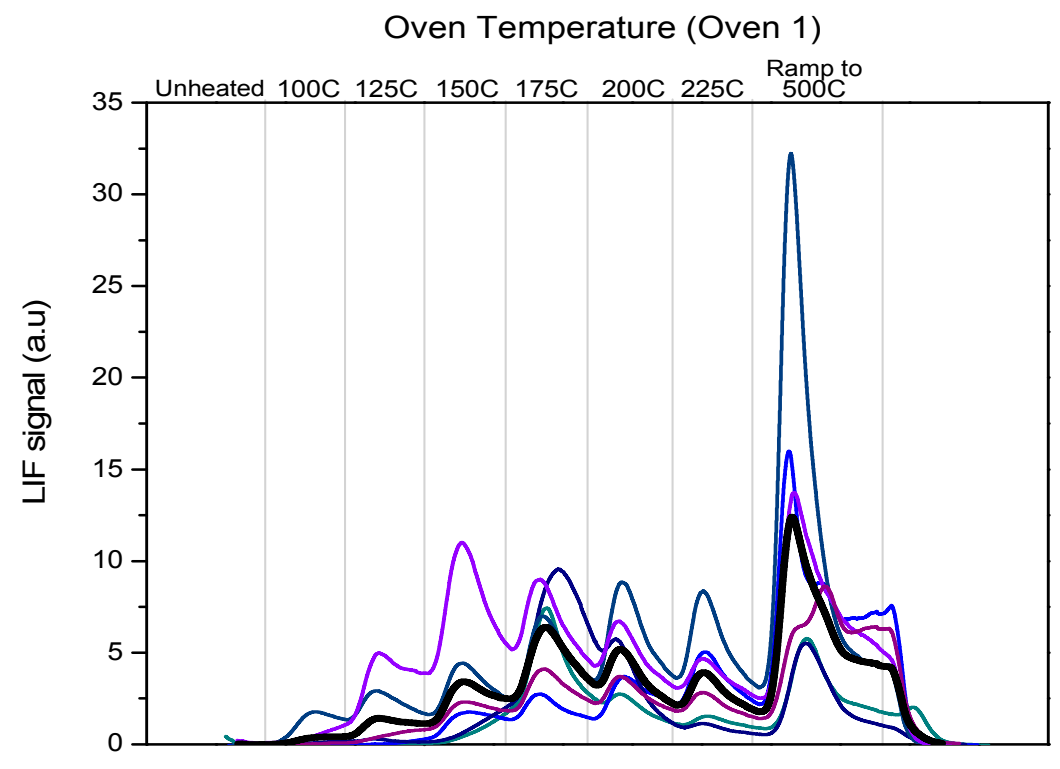


Figure 1 indicates the reproducibility of $6 \mathrm{PTD}$ profiles obtained by depositing pure $\mathrm{HgCl}_{2}$ under nominally identical conditions. The $\mathrm{HgCl}_{2}$ loadings varied considerably. Possible reasons include fluctuations in the gas phase concentration of $\mathrm{HgCl}_{2}$, variations in denuder collection efficiency, and variation in competition between desorption of molecular $\mathrm{HgCl}_{2}$, which we would not detect, and decomposition to produce GEM which we do detect. We have found it difficult to develop stable sources of $\mathrm{HgCl}_{2}$ for calibration purposes and this represents a major challenge in this type of experiment.

As a result of time constraints we were only able to obtain a single calibration profile obtained for the "oven 2" profile which is shown in Figure 2.

Figure 2. PTD profile using Oven 2 program for an uncoated tubular denuder loaded with pure $\mathrm{HgCl}_{2}$.

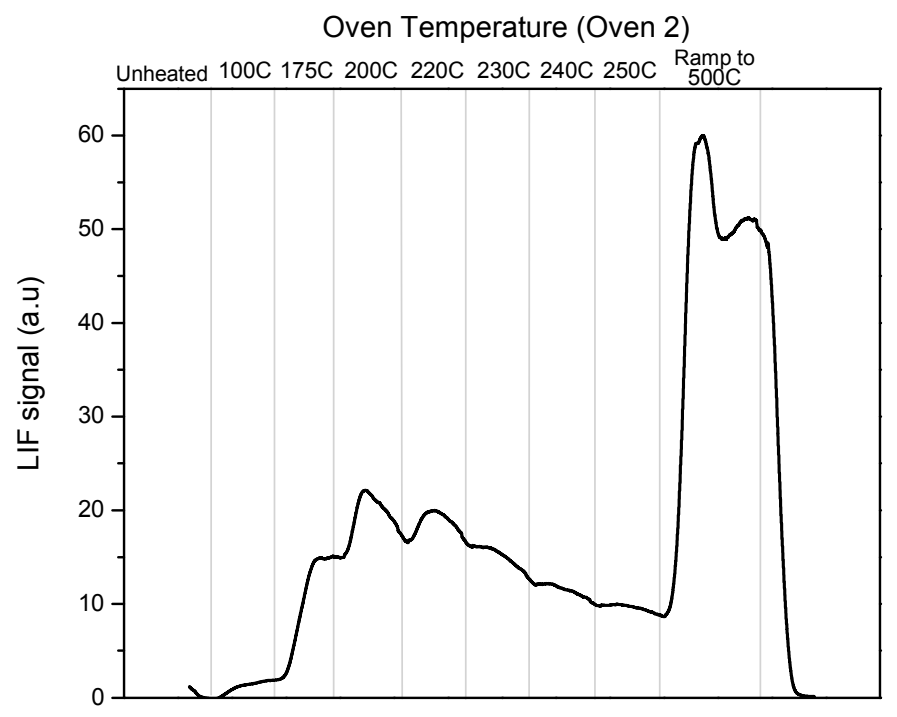

Some of the variability in the shape and structure of the PTD profiles has been determined to be a function of the deposition pattern of RGM on the denuder, the very significant temperature gradient along the denuder during the heating cycle, and the direction of buffer gas flow during both sampling and analysis. During the Crist measurements RGM was sampled over the whole denuder surface including the ends that are located outside of the oven and the direction of gas flow was not noted during sampling. As discussed below, we have found that during the heating cycle the center portion of the denuder heats most rapidly and the initial production of GEM reflects dissociation of RGM in this section of the denuder. The temperature in the PTD profile figures is the temperature as read by the oven thermocouple and most closely reflects the temperature of the central section of the denuder; the ends of the denuder are significantly cooler. As the temperature increases RGM deposited further from the center reaches decomposition temperature and the final ramp produces decomposition over most of the length of the tube. The oscillations in the PTD profiles appear to be the result of this effect in conjunction with the "ramp and hold for 5 min" sequence that we used for temperature ramping at Crist.

In addition, RGM deposition appears to be a function of flow direction, presumably maximum deposition occurs as the flow enters the denuder and decreases as the RGM concentration is depleted as the gas flows down the denuder. The flow-effect becomes more significant as the RGM loading 
increases. One consequence of the flow-effect is that dissociation profiles are more reproducible if the direction of gas flow through the denuder is the same during sampling and analysis. Since the direction of the sampling flow was not noted during stack sampling, this variation, together with a lack of reproducibility in the oven cycling, contributes to variation in the PTD profiles. The "post-Crist" improvements that have eliminated these problems are discussed below. Nonetheless, these issues affect the work at Crist and the initial calibration profiles obtained at the end of the campaign. In spite of this, the unique nature of the sampling opportunity, with simultaneous measurements in the stack and plume do allow us to draw useful conclusions, as we discuss below.

\subsection{Stack PTD Profiles}

Figure 3b shows PTD profiles for several stack samples analyzed using the "oven 2" thermal cycle described below. The "oven 2" PTD profile for pure $\mathrm{HgCl}_{2}$ (Figure 2) is shown again for comparison in Figure 3a. The stack profiles show a sharp onset of RGM dissociation at $\sim 200{ }^{\circ} \mathrm{C}$. GEM continues to evolve as the temperature increases, with a spike in RGM dissociation as the oven temperature is ramped to $500{ }^{\circ} \mathrm{C}$. The profiles are similar to the calibration $\mathrm{HgCl}_{2}$ profiles although the onset of dissociation occurs at a slightly lower temperature in the $\mathrm{HgCl}_{2}$ profiles. Nevertheless, the profiles shown in Figure 3 are quite similar and consistent with the $\mathrm{HgCl}_{2}$ calibration profile and the onset of RGM dissociation was quite consistent. The observation that these profiles are consistent with the $\mathrm{HgCl}_{2}$ profiles does not constitute a definitive identification of $\mathrm{HgCl}_{2}$.

Figure 3. Panel (A). Calibration profile obtained using Oven 2 program for denuder loaded with pure $\mathrm{HgCl}_{2}$; Panel (B). Dissociation profiles obtained using Oven 2 program for stack samples collected 18, 27 and 28 February 2008.

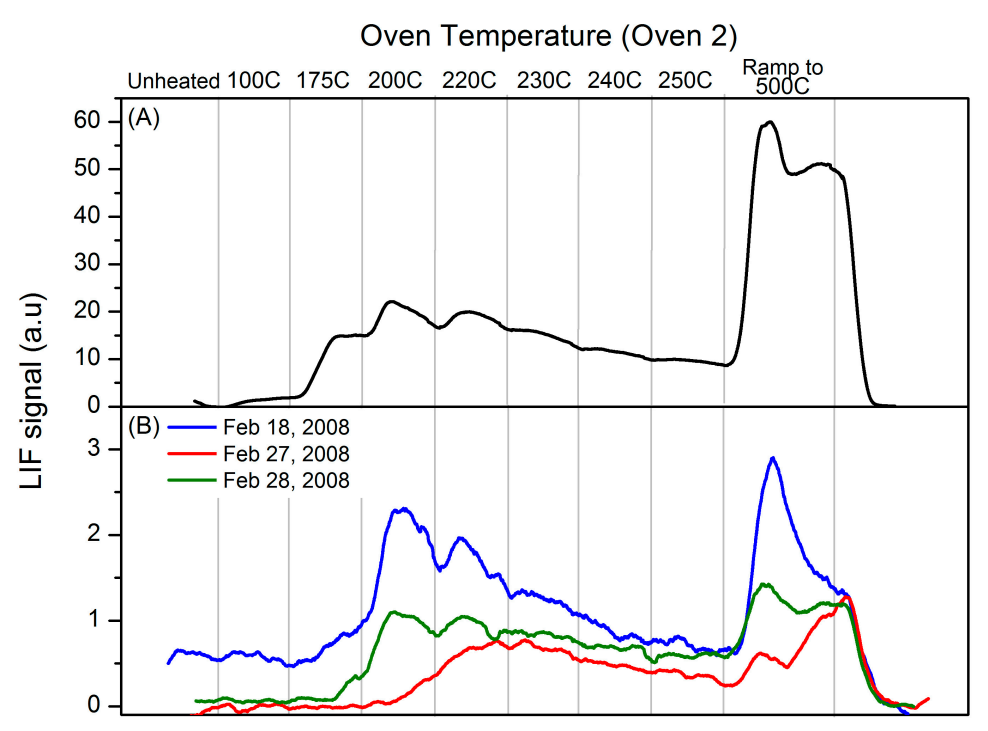

Figure $4 \mathrm{~b}$ shows PTD profiles of stack samples analyzed with the "oven 1" cycle described below together with the averaged "oven 1" PTD profile of $\mathrm{HgCl}_{2}$ shown in Figure 4a. The grey shading in this and subsequent "oven 1" PTD figures spans the minimum and maximum signals observed. The "oven 1" profiles have a slower temperature ramp between 100 and $200{ }^{\circ} \mathrm{C}$; however, we saw no evidence for any RGM species with a lower peak decomposition temperature. The "oven 1" PTD 
profile for pure $\mathrm{HgCl}_{2}$ shows measurable decomposition at $100{ }^{\circ} \mathrm{C}$ and typically peaks at $\sim 200{ }^{\circ} \mathrm{C}$. In the "oven 1" PTD profiles of stack samples, decomposition begins at a slightly higher temperature but the peak decomposition temperatures of the majority of the stack PTD profiles are consistent with $\mathrm{HgCl}_{2}$ being the sampled component of the deposited RGM. We should emphasize that this does not identify or prove that the compound is $\mathrm{HgCl}_{2}$; however, we do not see any evidence for a species with a peak decomposition temperature that is significantly lower and could clearly be identified as not being consistent with $\mathrm{HgCl}_{2}$.

Figure 4. Panel (A): Calibration profile obtained from average of six PTD profiles using Oven 1 program for denuder loaded with pure $\mathrm{HgCl}_{2}$. The grey shading spans the minimum and maximum signals observed; Panels (B,C): Dissociation profiles obtained using Oven 1 program for stack samples collected 18, 23 and 29 February 2008.

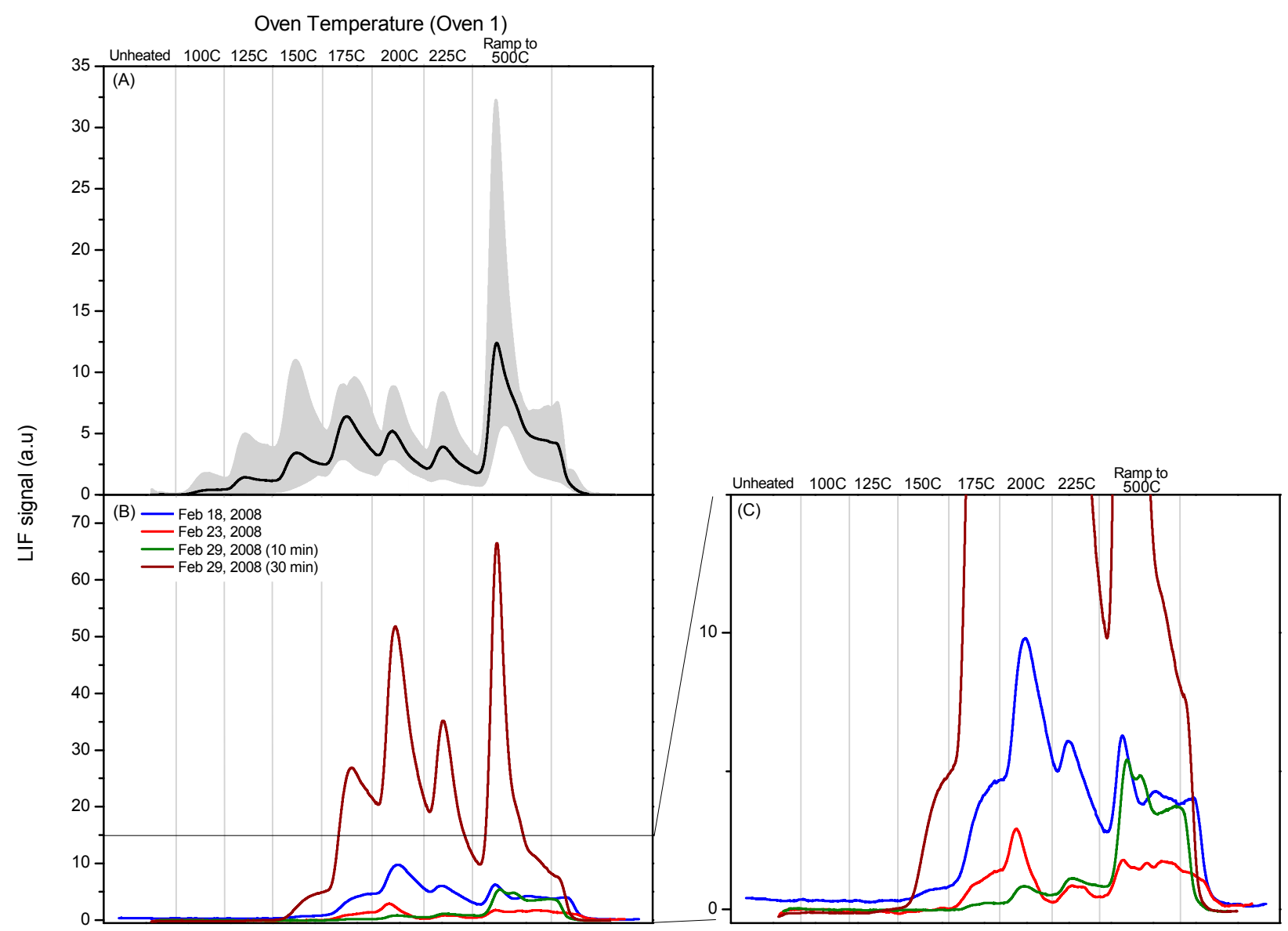

As we discuss above, the variation and reproducibility of the PTD profiles is a function of the deposition pattern, the temperature gradient, reproducibility of oven temperature cycling, and the direction of gas flow during both sampling and analysis. During stack sampling it is reasonable to assume that a variety of compounds that are present in the stack gas are being co-deposited on the denuders and this may have some impact both on the decomposition temperature and the competition between desorption and decomposition. It is also possible that chemical reactions can take place on the surface of the denuder between deposited RGM and other components of the stack gas. In-situ spiking of the stack gas with $\mathrm{HgCl}_{2}$ could address the impact of co-deposition effects. 


\subsection{In-Plume Sampling}

Figure 5b shows profiles from 28 February, showing the similarity in PTD profiles sampled in the stack and plume. The upwind sample was located approx. $4 \mathrm{~km}$ upwind of the Crist plant, Close-in was a sample collected approx. $0.6 \mathrm{~km}$ downwind of the Crist plant and further-out was a sample collected approx. $1.5 \mathrm{~km}$ downwind of the Crist plant.

Figure 5. Panel (A): Calibration profile obtained from average of six PTD profiles using Oven 1 program for denuder loaded with pure $\mathrm{HgCl}_{2}$. The grey shading spans the minimum and maximum signals observed; Panel (B): Dissociation profiles obtained using Oven 1 program for airship samples collected 28 February 2008.

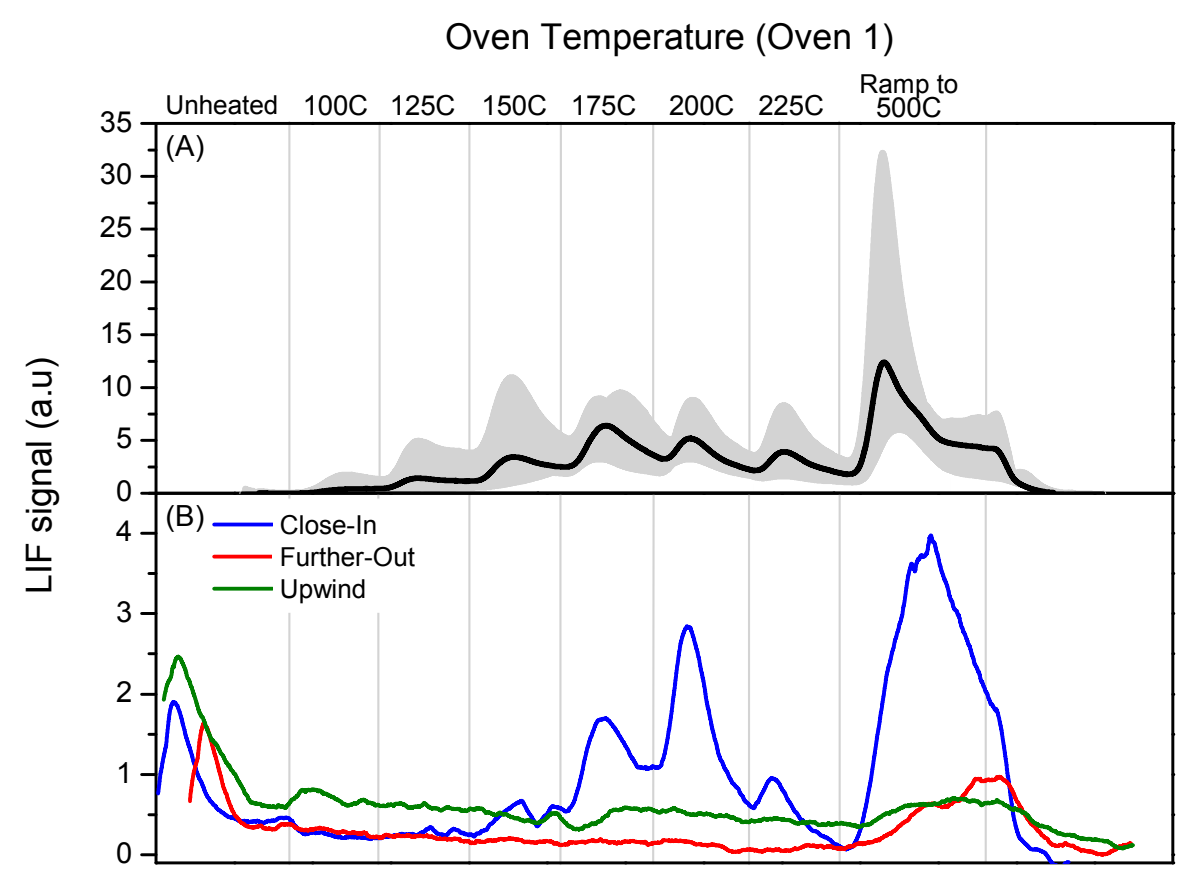

The "close-in" sample shows a well-defined thermal dissociation profile that is similar to the stack profile of the morning of the 29 February 2008, as seen in Figure 4, burning an identical coal mixture. The airship profiles show a GEM signal that occurs prior to the heating cycle. This preheat mercury signal was observed in all of the airship samples including those that were not able to detect any plume RGM. No preheat mercury signal was observed in any of the stack samples. This could be a result of a contamination problem in the adapters used to plumb the screw-end denuders into the analysis gas flow system but its origin was not identified. Figure 6 shows the PTD profiles of $\mathrm{HgCl}_{2}$, the "close-in" blimp sample and the stack sample from the morning of the 29 February 2008.

The similarity between the PTD stack and blimp profiles and their similarity to the $\mathrm{HgCl}_{2}$ profile suggest that the species sampled from the stack and the plume are the same and are consistent with the chemical speciation of the sampled $\mathrm{RGM}$ being $\mathrm{HgCl}_{2}$. The coal that was used during this sampling period contained the highest level of chlorine seen during the Crist campaign, constituting $97 \%$ of the total halogens with a bromine content of $0.16 \%$ and fluorine as the balance. Comparing PTD profiles of $\mathrm{HgCl}_{2}$ with the PTD profiles of the stack and plume samples suggests they are consistent with $\mathrm{HgCl}_{2}$ as the specific chemical speciation of sampled stack RGM but, as discussed 
above, this does not prove that the stack $\mathrm{RGM}$ is $\mathrm{HgCl}_{2}$. It could also consist of other oxidized mercury compounds that have a similar PTD profile to $\mathrm{HgCl}_{2}$. One possible explanation of the observations of Edgerton et al. [1] is that a component of RGM undergoes slow thermal decomposition at ambient temperatures. No evidence for a significant component of the RGM sample that has a significantly lower decomposition temperature than $\mathrm{HgCl}_{2}$ was observed.

Figure 6. Panel (A): Calibration profile obtained from average of six PTD profiles using Oven 1 program for denuder loaded with pure $\mathrm{HgCl}_{2}$. The grey shading spans the minimum and maximum signals observed; Panel (B): Dissociation profiles obtained using Oven 1 program for "close-in" airship sample collected 28 February 2008; Panel (C): Dissociation profiles obtained using Oven 1 program for stack sample collected 29 February 2008.

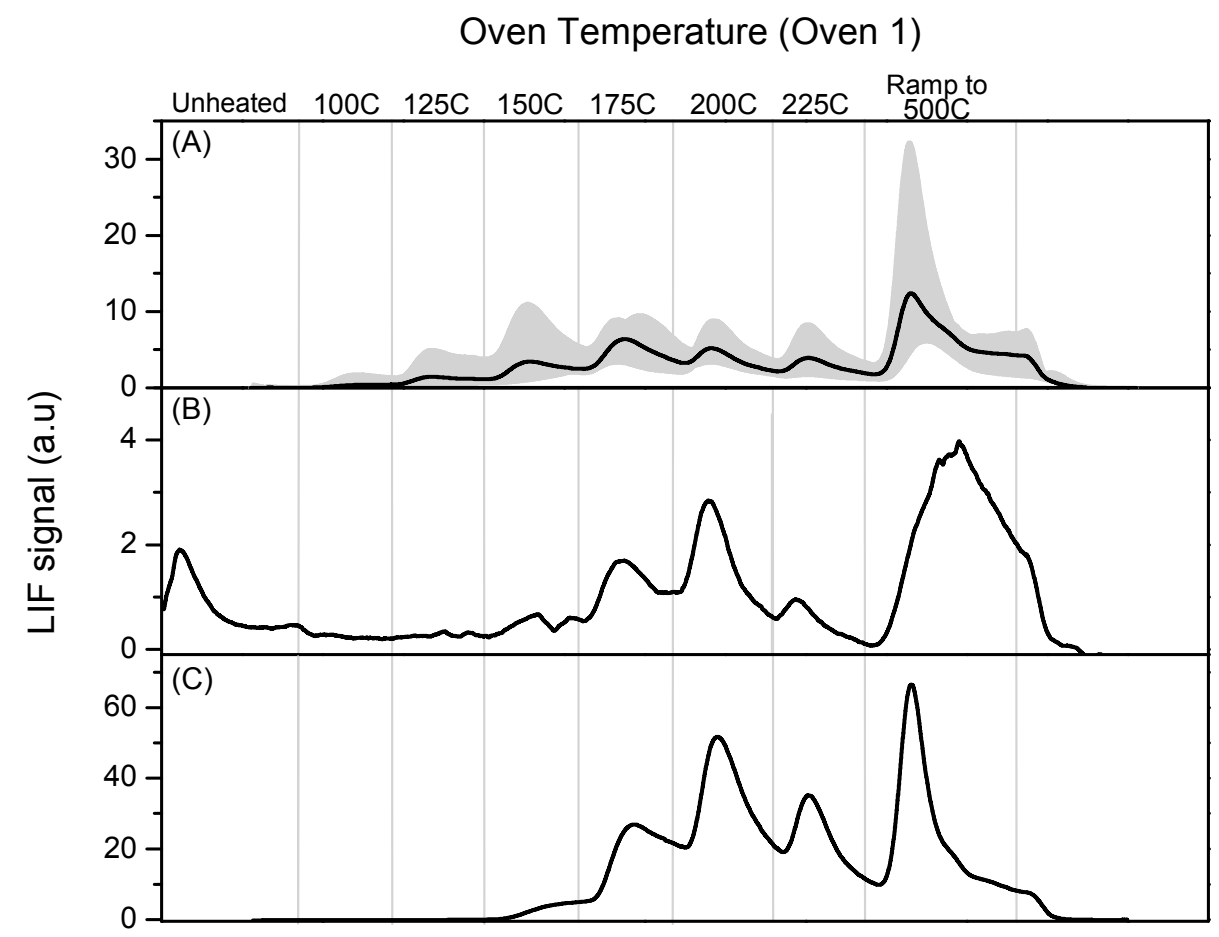

\subsection{Denuder Sampling Efficiencies}

The objective of this component of the Crist study was to investigate the potential of PTD for chemical speciation of RGM. The collection efficiency of the denuder is not known and PTD will not give a quantitative measurement of RGM concentration under these conditions. However, the PTD profiles were also calibrated for $\mathrm{Hg}^{\circ}$ as discussed in Section 2.6. This provides an approximate measure of the total amount of RGM collected on the denuder. Since the RGM stack concentrations were measured independently, we can obtain an approximate measure of the sampling efficiency of the denuders as a check on the integrity of the measurements. For example, a sampling efficiency in excess of $100 \%$ would imply major problems with denuder contamination.

All denuder sampling was performed under laminar flow conditions and a theoretical sampling efficiency can be estimated using the Gormley-Kennedy equation [14]. This assumes laminar flow and a sticking coefficient of 1 and requires a tube diameter and a flow rate, which are known, and a diffusion coefficient for the species of interest, which is not known. If a diffusion coefficient of 
$0.1 \mathrm{~cm}^{2} \cdot \mathrm{s}^{-1}$ is assumed, a typical value for molecules in air, we calculate a sampling efficiency of $\sim 60 \%$ for the stack sampling and $\sim 70 \%$ for plume sampling. If we assume that the chemical identity of the $\mathrm{RGM}$ is $\mathrm{HgCl}_{2}$, we can estimate a diffusion coefficient of $0.04 \mathrm{~cm}^{2} \cdot \mathrm{s}^{-1}$ using the mass relationship from Schwarzenbach et al. [15] and this would give calculated sampling efficiencies of 35\% and $43 \%$ at the stack and plume sampling flow rates.

To estimate the actual denuder sampling efficiencies, the total amount of RGM that was sampled was calculated from the stack RGM concentrations as measured by the CEMS instrumentation and sampling flow rate through the denuder. The RGM that was actually deposited on the denuder was taken from the total calibrated PTD profiles and included the final peak obtained during the temperature increase to $500{ }^{\circ} \mathrm{C}$. The RGM actually deposited on the denuder was then divided by the calculated total sampled amount based on the flow and stack concentrations. This then gives an estimate of the denuder sampling efficiency, i.e., the amount of RGM collected on the denuder compared with the total amount of RGM that was sampled from the stack and then flowed through the denuder, but did not necessarily deposit on the walls. These sampling efficiencies are estimates since some RGM was deposited on the ends of the denuders and was not measured. As noted above, it is possible that some of the deposited RGM evaporated before decomposition to $\mathrm{Hg}^{\circ}$ and this would not have been measured.

The efficiencies for stack profiles shown in the figures are given in Table 1. A total of 28 stack profiles were analyzed with sampling efficiencies that ranged from $\sim 1 \%$ to $55 \%$. Sampling efficiencies from samples obtained with the particle filter in place were typically much lower than estimated from the Gormley-Kennedy equation, ranging from $\sim 1 \%$ to $30 \%$. Three PTD stack profiles were obtained without the particle filter in the sampling stream and the calculated sampling efficiencies were $50 \%$, $55 \%$ and $37 \%$, much closer to the estimated values so it appears that the presence of the filter significantly reduced the sampling efficiency. This does not appear to be due to collection of particulate mercury when the filter was removed. These samples were obtained downstream of the electrostatic precipitator and Ontario Hydro measurements found that the concentration of particulate mercury was below detection limits. We have looked at the variability in greater detail. Based on a total of 24 samples taken with the filter the mean and standard deviation of the $\mathrm{RGM} / \mathrm{m}^{3}$ is $0.46 \pm 0.66 \mathrm{ug} / \mathrm{m}^{3}$, taking only samples collected using etched denuders we obtain $0.25 \pm 0.19 \mathrm{ug} / \mathrm{m}^{3}$ and those analyzed using the oven 2 cycle $0.35 \pm 0.24 \mathrm{ug} / \mathrm{m}^{3}$. For the samples taken without the filter the average is $2.7 \pm 1.0 \mathrm{ug} / \mathrm{m}^{3}$. It is clear that the presence of the quartz filter significantly reduced the collection efficiency and we have no explanation for this. The significant variability is also clear and it does not appear to be explained by differences in analysis, i.e., oven program, or tube etching.

In Figure 7 we show PTD profiles of two samples taken within a 24-h period burning identical coals. One, a 30 min stack sample from 29 February was taken with the filter in place, while the other, a 10 min stack sample from March 1st was taken without the filter. The similarity between the profiles suggests that the filter did not affect the speciation of the deposited RGM, while the difference in sampling time shows the reduced collection efficiency when the filter was in place. It is important to also recognize that the measured RGM in the stack gas was variable and there was disagreement of up to $40 \%$ in the stack RGM measurements using different approaches. 
Figure 7. Comparison of PTD profiles (using Oven 1 program) of a 30 min stack sample obtained on 29 February 2008 with the particle filter in place and a 10 min stack sample obtained on 1 March 2008 without the particle filter.

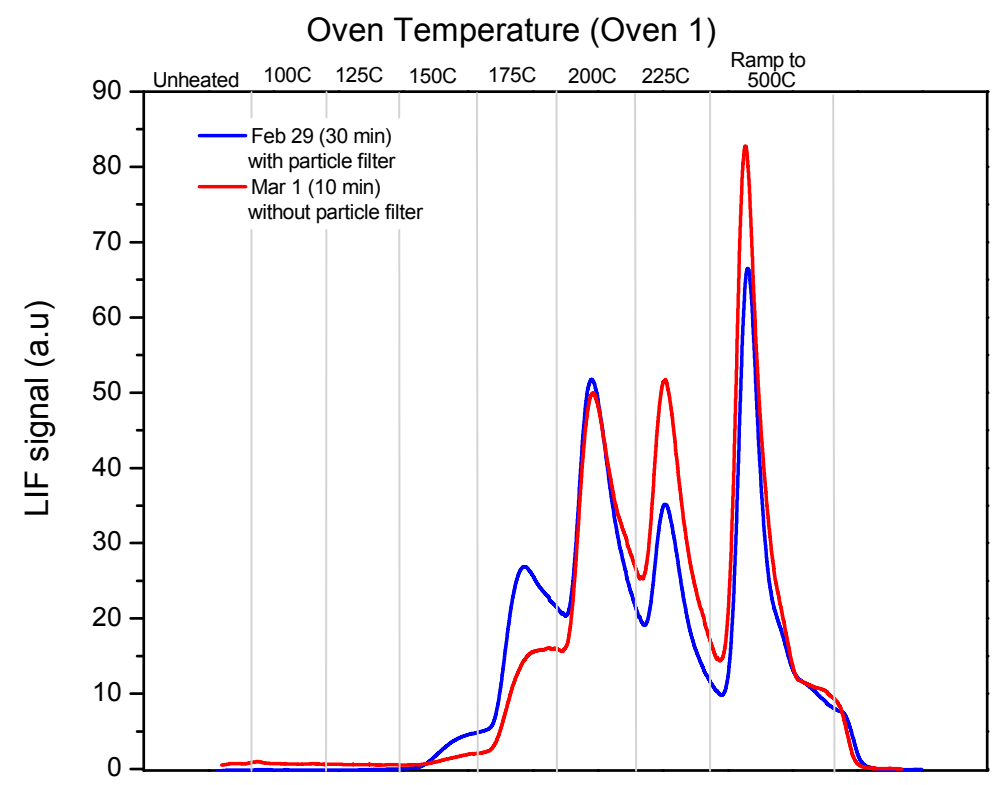

An estimate of the collection efficiency of the in-plume samples requires a comparison between sampled RGM and that predicted using the measured stack concentrations and calculated plume dilution ratios. Dilution ratios were based on the measured concentrations of three tracer gases, $\mathrm{SO}_{2}$, $\mathrm{NO}_{\mathrm{y}}$ and $\mathrm{CO}_{2}$, which were measured in stack and also in the airship. Figure 8 shows the "background corrected" concentrations of $\mathrm{SO}_{2}, \mathrm{NO}_{\mathrm{y}}$ and $\mathrm{CO}_{2}$ as measured by the airship's sampling system during the 75-min "close-in" sampling run on 28 February.

Figure 8. "Background corrected" concentrations of $\mathrm{SO}_{2}, \mathrm{NO}_{\mathrm{y}}$ and $\mathrm{CO}_{2}$ as measured by the airship's sampling system during the "close-in" sampling run on 28 February.

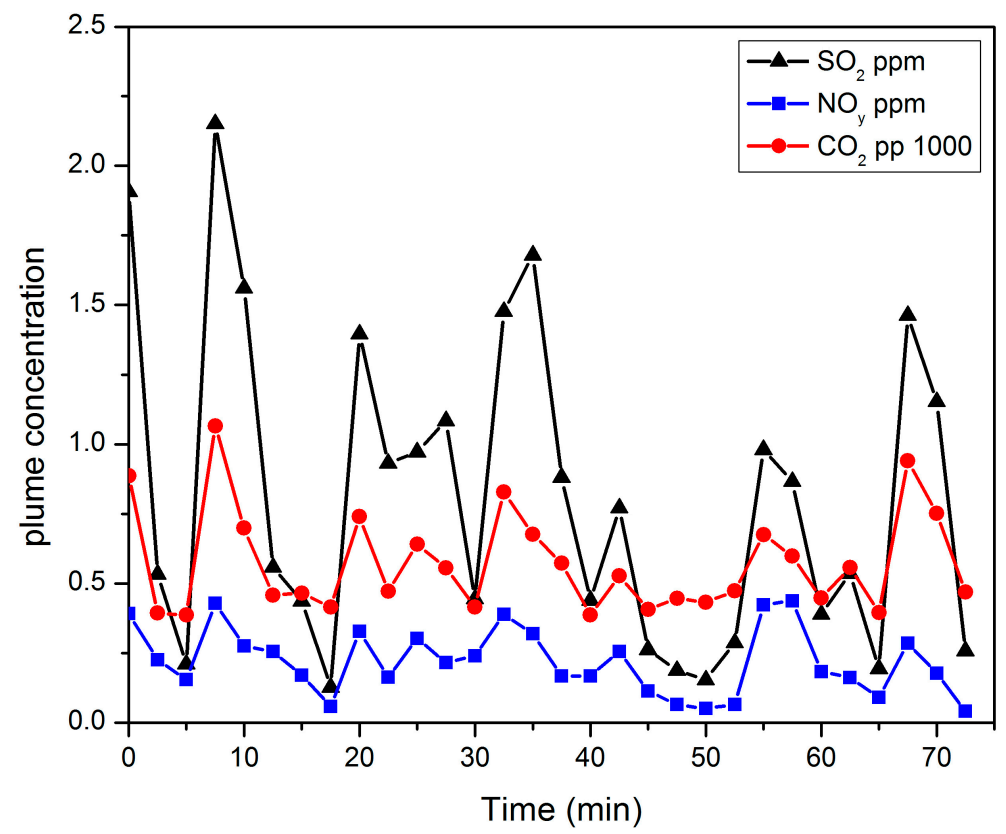


The background correction was obtained by subtracting the concentrations measured upstream of the plume. The concentrations shown in Figure 8 reflect the increase in the concentration of these gases over ambient as the plume gases mix with ambient air. There was little variation in the stack concentrations during the sampling period and the observed variations reflect the difficulties of keeping the airship's sampling system in the plume. The measured airship concentrations of $\mathrm{SO}_{2}, \mathrm{NO}_{\mathrm{y}}$ and $\mathrm{CO}_{2}$ can be used to calculate the dilution of the plume gases as the plume evolved and mixed with ambient air. Because of the variation in concentration, the dilution ratios were calculated for 2.5 min coincident time bins for each tracer gas. The calculated dilution ratio for each tracer gas was then multiplied by the stack RGM concentration measured by the CEMS instrumentation to calculate the mass of RGM sampled by the denuder during each $2.5 \mathrm{~min}$ bin. This was summed to calculate the total mass of RGM sampled by the denuder during the 75-min sampling period based on each tracer dilution ratio. Table 1 shows the calculated total amount of RGM sampled by the denuders at the "close-in" and "further-out" positions. These amounts are calculated from the RGM concentration measured in the stack by the CEMS instrument and the calculated dilution ratio from each tracer. The difference between the values calculated using the three tracers reflects the fact that the three tracers give different integrated dilution ratios, an indication of the difficulty of the measurement.

Table 1. Estimated denuder collection efficiencies for in-plume samples obtained 28 February 2008.

\begin{tabular}{|c|c|c|c|c|c|c|c|c|}
\hline \multirow[t]{2}{*}{$\begin{array}{l}\text { Airship } \\
\text { Sample }\end{array}$} & \multirow[t]{2}{*}{ Denuder Type } & \multirow[t]{2}{*}{$\begin{array}{l}\text { Actual RGM * } \\
\text { Deposited on } \\
\text { Denuder (ng) }\end{array}$} & \multicolumn{3}{|c|}{$\begin{array}{c}\text { Total RGM ** Sampled by } \\
\text { Denuder (ng) as Calculated } \\
\text { from Dilution Ratios } \\
\end{array}$} & \multicolumn{3}{|c|}{$\begin{array}{c}\text { Denuder Collection Efficiency } \\
\text { (\%) as Calculated from } \\
\text { Dilution Ratios } \\
\end{array}$} \\
\hline & & & $\mathrm{SO}_{2}$ & $\mathrm{NO}_{\mathrm{y}}$ & $\mathrm{CO}_{2}$ & $\mathrm{SO}_{2}$ & $\mathrm{NO}_{\mathrm{y}}$ & $\mathrm{CO}_{2}$ \\
\hline "Close-in" & unetched quartz & 1.19 & 1.78 & 2.16 & 1.19 & 67 & 55 & 100 \\
\hline "Further-out" & unetched pyrex & 0.13 & 0.41 & 0.73 & 0.41 & 32 & 18 & 32 \\
\hline
\end{tabular}

* As determined using PTD technique; ** Based on CEMS stack concentration and calculated dilution ratio for each tracer.

The observation of the early $\mathrm{Hg}^{\circ}$ signal and the drifting baseline complicate the analysis of the dissociation profiles in Figure 3. The "close-in" profile shows a well-defined dissociation profile between $150-225{ }^{\circ} \mathrm{C}$ and a larger area in the final ramp to $500{ }^{\circ} \mathrm{C}$. Taking the total integrated sample gives $\sim 1.3 \mathrm{ng}$ of $\mathrm{Hg}^{\circ}, 0.61 \mathrm{ng}$ in the structured profile and $0.66 \mathrm{ng}$ in the final ramp to $500{ }^{\circ} \mathrm{C}$. If we take the $0.08 \mathrm{ng}$ from the upwind sample as our field blank we calculate $0.13 \mathrm{ng}$ of RGM deposited on the "further-out" denuder and $1.19 \mathrm{ng}$ deposited on the "close-in" denuder. If we then compare this with the total RGM sampled by the denuders, as calculated from dilution ratios, we find sampling efficiencies of $67 \%$ and $55 \%$ using the $\mathrm{SO}_{2}$ and $\mathrm{NO}_{\mathrm{y}}$ dilution ratios and $100 \%$ from the $\mathrm{CO}_{2}$ dilution ratio. For the "Further-out" denuder we calculate sampling efficiencies of $32 \%, 18 \%$ and $32 \%$ respectively. Given the large uncertainty in the dilution ratios these efficiencies suggest that the RGM sampled in-plume is consistent with the levels measured by the CEMS instrument in the stack. This, together with the PTD profiles of the stack and plume samples shown in Figure 6 suggests that it is possible to use PTD to measure a component of RGM in the stack and follow its evolution in the plume. It also suggests that the speciation of the RGM is not changed during this period and that 
it is consistent with $\mathrm{HgCl}_{2}$ as the speciation of RGM. This can be compared with the observations of Deeds et al. [4] who found greatly decreased levels of RGM and no mass balance.

\subsection{RGM Speciation}

As we have noted above, it is important to emphasize that the generally held opinion that $\mathrm{HgCl}_{2}$ is the species of RGM emitted from coal-fired power plants is not based on any experimental evidence, or on any reasonable mechanism for homogeneous formation of $\mathrm{HgCl}_{2}$ in coal combustion. The PTD profiles shown here are clearly consistent with identifying the speciation of stack and plume RGM as $\mathrm{HgCl}_{2}$ and represent the first actual experimental evidence that is consistent with $\mathrm{HgCl}_{2}$ speciation. It is reasonable to ask if any other mercury species is consistent with the observed PTD profiles. As we have noted previously, all of the mercuric halides are stable gas phase species; however, for most of the coal burned during the Crist campaign more than 95\% was present as $\mathrm{Cl}$ and less than $1 \%$ was present as $\mathrm{Br}$, hence $\mathrm{HgBr}_{2}$ is not viable as an $\mathrm{RGM}$ candidate. Sulfur typically constituted $1 \%$ by weight of the coal burned; however, $\mathrm{HgS}$ is not a stable gas phase species [16] and the PTD profiles of $\mathrm{HgS}$ are not consistent with our observations.

The reported PTD profiles for solid $\mathrm{HgO}$ [11-13] are much more variable with peak decomposition temperatures ranging from $260{ }^{\circ} \mathrm{C}$ to $600{ }^{\circ} \mathrm{C}$, but are not consistent with the decomposition seen in oven 1 profiles. Earlier work [8] suggested that $\mathrm{HgO}$ could be a significant component of RGM at stack gas temperatures in excess of $450{ }^{\circ} \mathrm{C}$. However, recent high level ab-initio calculations [17] have shown that $\mathrm{HgO}$ cannot exist as a stable diatomic molecule in the gas phase. The implications of this for the atmospheric chemistry of mercury have been discussed in detail elsewhere [18] but it is clear that even in lean flames $\mathrm{HgO}$ can play no role in $\mathrm{Hg}$ oxidation and cannot be a candidate for stack RGM. It should be noted that Donohoue [9] reported PTD profiles for $\mathrm{HgO}$ that were thought to be from gas phase deposition. These profiles showed decomposition at low temperatures but it is now clear that these profiles were an artifact that resulted from contamination in sample lines. We have measured PTD profiles of solid $\mathrm{HgO}$ and find that it decomposes at a significantly higher temperature than $\mathrm{HgCl}_{2}$.

It is clear, therefore, that $\mathrm{HgCl}_{2}$ is the only stable $\mathrm{Hg}(\mathrm{II})$ species with an observed PTD profile that is consistent with our stack and plume PTD profiles and is the most likely candidate for the actual species.

In spite of the caveats associated with the fact that this was the first attempt to do this kind of sampling and analysis in a working coal-fired power plant, our experimental evidence, sampling from both stack and plume, suggests that $\mathrm{HgCl}_{2}$ is indeed the emitted form of $\mathrm{RGM}$. To the best of our knowledge this is the first and only set of experimental evidence that addresses this speciation issue. It suggests that attempts to understand and model in-plume reduction of RGM to GEM should use $\mathrm{HgCl}_{2}$ as the speciation of RGM.

\subsection{Further Development of the PTD Approach}

In continuing development of the PTD approach, focus was on the use of uncoated quartz tubular denuders with an etched central area. The control of the oven ramping temperature is critical for reproducible PTD profiles and we have eliminated the use of a PID temperature controller and 
the type of "ramp and hold" cycles that were used during the Crist campaign. In addition, by using an etched central portion of the denuders it is possible to completely eliminate the large peak that is associated with the final temperature ramp. Typically we now use $5 \mathrm{~min}$ of preheating at $50{ }^{\circ} \mathrm{C}$ and then a constant ramp from 50 to $500{ }^{\circ} \mathrm{C}$. Supplemental Figure $\mathrm{S} 1$ shows PTD profiles of $\mathrm{HgCl}_{2}$ deposited on etched quartz denuders that are obtained using this $50-500{ }^{\circ} \mathrm{C}$ ramping sequence. The mass of $\mathrm{HgCl}_{2}$ deposited varies between 20 and $50 \mathrm{pg}$, i.e., more than an order of magnitude lower than deposited during the Crist campaign. The profiles are quite reproducible and eliminate the "final ramp" peak and oscillations that are particularly evident in the "oven 1" profiles. The PTD profiles of $\mathrm{HgCl}_{2}$ and $\mathrm{HgBr}_{2}$ were compared and are identical on uncoated tubular denuders. However, this is not relevant to the Crist work because chlorine was the dominant halogen component of all the coal that was burned during the Crist campaign. In contrast, we find that solid samples of $\mathrm{HgO}$ and a compound deposited from the heterogeneous reaction of mercury and ozone have PTD profiles that decompose at significantly higher temperature than $\mathrm{HgCl}_{2}$. In other work from this laboratory uncoated quartz denuders with an etched central surface were used to sample from a small aircraft over Mississippi and the Gulf of Mexico. Several samples show evidence for an RGM species that decomposes at a significantly lower temperature than $\mathrm{HgCl}_{2}$ or $\mathrm{HgBr}_{2}$ together with samples that decompose at temperatures that are consistent with the PTD profiles of these mercuric halides. Examples of two such profiles are shown in Supplemental Figures S2 and S3. Figure S2 shows a PTD profile of a high altitude sample with a total mass of $58 \mathrm{pg}$. Figure S3 shows a PTD profile of a sample taken at $500 \mathrm{ft}$ in the marine boundary layer over the Gulf of Mexico with a total mass of $56 \mathrm{pg}$. In both cases the PTD profiles of the flight blanks are shown. These observations are significant in that they may imply there is a form of atmospheric RGM with a PTD profile which is not consistent with speciation as either $\mathrm{HgCl}_{2}$ or $\mathrm{HgBr}_{2}$; however, we saw no evidence for the presence of this species in the Plant Crist plume.

\section{Experimental Section}

\subsection{Conventional Denuder Sampling}

Since PTD is not a commonly used analytical method, it is useful to contrast the PTD technique with "conventional denuder sampling" as a route to the measurement of total RGM concentrations. The use of $\mathrm{KCl}$ coated annular denuder sampling coupled with thermal dissociation has been described by Landis et al. [19] and forms the basis of a commercially available RGM measurement system, the Tekran Model 1130 Mercury Speciation Unit (Tekran, 2010). In this instrument air is pulled through a $\mathrm{KCl}$ coated annular denuder that captures RGM but transmits elemental and particulate mercury. After a period of sampling, the denuder is flushed with zero air and the denuder is heated to $500{ }^{\circ} \mathrm{C}$. The RGM is thermally decomposed producing elemental mercury that desorbs from the denuder surface and is then captured by a Tekran 2537 Mercury vapor analyzer. In the Tekran 2537 the elemental mercury is collected by amalgamation on a gold cartridge during a sampling phase. The instrument is then flushed with argon and the mercury desorbed by heating the gold cartridge. The desorbed gas phase mercury is detected by Cold Vapor Atomic Fluorescence Spectrophotometry (CVAFS). 


\subsection{Programmable Thermal Dissociation}

In PTD, the evolution of GEM is monitored as a function of temperature in real time during pyrolysis of a sample. PTD could be considered to be somewhat analogous to thermogravimetric analysis. However, in PTD the evolution of a gas phase product is monitored, rather than monitoring the decrease in the weight of the sample. It has been used to examine mercury speciation in solids [10-13] and a comparison of the PTD profiles reported in these works and measured here was discussed in Section 2.3.

In contrast to the studies of mercury containing solids, the configuration of PTD utilized in this work is designed to sample gas phase RGM. During the thermal analysis we use laser-induced fluorescence to monitor the extent of RGM decomposition as a function of temperature in real time by measuring the evolution of GEM produced during decomposition. The RGM sample is obtained by pulling the analysis gas through a quartz or Pyrex tube that acts as a denuder and captures RGM but transmits elemental and particulate mercury. It should be emphasized that these are uncoated tubular denuders in contrast to the $\mathrm{KCl}$ coated annular denuders that are commonly used to quantify total RGM [19]. The collection efficiency of the denuder is not known and, in this configuration, PTD is not designed to produce a quantitative measurement of RGM concentration. After a period of sampling the denuder is transported to a laboratory, flushed with $\mathrm{He}$ and then heated in a series of temperature ramps in an oven. As the denuder temperature increases, RGM dissociates and the GEM product is desorbed from the denuder wall. The GEM evolution is monitored in real time using laser-induced fluorescence (LIF). Comparison of the PTD profiles of unknown samples with profiles of known oxidized mercury compounds may provide information on the chemical identity of the sample. Since PTD is an indirect technique and different compounds can have identical or very similar decomposition properties it is unlikely to provide a definitive molecular identification. However, it should be possible to indicate whether the PTD profile of a sample is consistent with a particular molecular species or class of species.

\subsection{Denuder Sampling}

\subsubsection{Sampling during the Crist Campaign}

Field sampling at CFPP Crist took place between 18 February and 1 March 2008. The plant has four coal-fired units, two of which were operational during the campaign. The operational units, \#6 (320 MW) and \#7 (500 MW) shared a common stack and mercury continuous emissions monitoring systems (CEMS) were located at the output of each unit prior to discharge into the stack. In addition to the mercury CEMS, independent measurements of mercury concentration were made using the Ontario Hydro method and sorbent traps. $\mathrm{NO}_{\mathrm{x}}, \mathrm{SO}_{2}$ and $\mathrm{CO}_{2}$ were measured by the Crist CEMS instrumentation. Mercury emissions were dominated by the exhaust from unit \#7, which typically contained $5-7 \mu \mathrm{g} \cdot \mathrm{m}^{-3}$ of mercury, more than $90 \%$ of which was present as RGM. The unit \#6 exhaust typically contained less than $1 \mu \mathrm{g} \cdot \mathrm{m}^{-3}$ of mercury and contained equal amounts of GEM and RGM. As a consequence, mercury in the stack gas was largely in the form of RGM. The Ontario Hydro and CEMS RGM stack measurements showed good agreement although the agreement between 
the GEM measurements was more problematic, reflecting the much lower concentrations of elemental mercury in the stack gas [6].

A preliminary laboratory assessment of the utility of PTD on $\mathrm{KCl}$ coated annular denuders is described by Donohoue [9]. Based on the prospect of sharper PTD profiles, together with time and cost limitations, uncoated tubular denuders were selected for PTD analysis during the campaign. A variety of quartz and Pyrex tubular denuders approximately $2.5 \mathrm{~cm}$ diameter and $50 \mathrm{~cm}$ long were used during the sampling campaign. Several of the denuders had a $25 \mathrm{~cm}$ central section that was etched to enhance the surface area. Denuders were prepared by rinsing with concentrated $\mathrm{KOH}$, followed by distilled water, $10 \%$ nitric acid solution, distilled water, and finally methanol. They were dried in air without heating.

It was necessary to analyze the denuders and then clean them for additional sampling, making on-site analysis desirable. Analysis was performed at the University of West Florida (UWF), located approximately $7 \mathrm{~m}$ from Plant Crist and $5 \mathrm{~m}$ from Pensacola Airport, the base of operations for the airship. Denuder sampling experience prior to the Crist campaign had been a limited set of laboratory studies and high levels of RGM in the stack and blimp samples that could be analyzed using single photon LIF were anticipated.

During the sampling campaign the dye laser that was used to excite fluorescence showed short-term drift, due to a damaged output coupler that had been degrading the Nd-Yag pump laser over the course of the two week sampling period, and possibly also due to temperature variation in the laboratory at UWF. This short-term drift produced background shifts in a number of the dissociation profiles.

\subsubsection{Stack Sampling}

All stack sampling was performed by personnel from the Energy and Engineering Research Center (EERC), University of North Dakota in conjunction with their measurements of GEM and RGM using the Ontario Hydro method. Stack gas samples were collected from ducts located after the electrostatic precipitator and prior to entering the stack. The gas was pumped from the ducts and diluted to prevent condensation. Most of the samples were obtained with a quartz particle filter in the sampling line. The filter was located in the stack and had a capture efficiency of $99.95 \%$ for $0.3 \mu \mathrm{m}$ particles. Typical sampling times were 1-30 min at the stack at 5 SLPM total flow (4.5 SLPM dilution air +0.5 SLPM stack gas). Typical stack gas temperatures at the sampling point were $\sim 150{ }^{\circ} \mathrm{C}$ and the gas had cooled to $\sim 25^{\circ} \mathrm{C}$ before reaching the denuder. After sampling, the denuders were capped, and once sampling was completed for the day they were transported to UWF for analysis. Denuders were stored in the analysis laboratory at room temperature and typically analyzed the day following sampling.

\subsubsection{In-Plume Sampling}

An airship was used to sample the exhaust plume with the objective of holding the sampling modules within the centerline of the plume at approximately the same position for an extended period of time. The sampling PVC modules were suspended 60 feet below the airship's gondola and connected by umbilical tubes that included sample lines connected to pumps in the gondola. In addition to denuders and filters located in the sampling modules, a dual TEKRAN system located in the gondola ran in parallel and measured total gaseous mercury (RGM + GEM) and GEM separately 
at 2.5 min intervals. In addition, $\mathrm{SO}_{2}, \mathrm{NO}_{\mathrm{y}}$, and $\mathrm{CO}_{2}$ were measured continuously and used as plume-detection tracers.

EPA personnel performed the in-plume sampling. The sampling module for the PTD denuders pulled air directly from the plume at ambient temperature and this was drawn though the denuder at 3.5 SLPM. After a sampling period of typically one hour the module was pulled up into the airship's gondola, the denuder was removed and capped, a fresh denuder loaded into the module, and the module lowered back into the plume for another period of sampling. After the airship landed the denuders were transported to UWF for analysis. A total of 20 uncoated tubular denuder samples were obtained on six days during the campaign. The airship's sampling protocol involved taking one sample upwind of the stack to establish background conditions followed by a sample downwind and close to the stack, and then a final sample further downwind in-plume; referred to as "close-in" and "further-out," respectively.

\subsection{Analysis by Programmable Thermal Dissociation (PTD)}

Analysis was performed using PTD, heating the denuders in a series of steps and monitoring the evolution of GEM as a function of time using single photon LIF. Analysis was performed in $\mathrm{He}$ buffer to enhance detection sensitivity for GEM. For analysis the denuders were placed in a clamshell furnace and flushed with $\mathrm{He}$ at $0.45 \mathrm{~L} / \mathrm{min}$ to remove all ambient gas and this flow was maintained for the full heating cycle. Two thermal cycles were used and are subsequently referred to as "oven 1 " or "oven 2 ". In the "oven 1" cycle the temperature was raised to $100{ }^{\circ} \mathrm{C}$ and then increased in five $25{ }^{\circ} \mathrm{C}$ ramps up to $225{ }^{\circ} \mathrm{C}$ with each ramping cycle taking $5 \mathrm{~min}$. Finally, the oven temperature was rapidly increased to $500{ }^{\circ} \mathrm{C}$ and held at this temperature for $5 \mathrm{~min}$. In the other cycle "oven 2 " the oven temperature was increased to $100{ }^{\circ} \mathrm{C}, 175{ }^{\circ} \mathrm{C}, 200{ }^{\circ} \mathrm{C}$, four $10{ }^{\circ} \mathrm{C}$ ramps to $250{ }^{\circ} \mathrm{C}$ and then rapidly increased to $500{ }^{\circ} \mathrm{C}$. Again each ramping step took $5 \mathrm{~min}$. The "oven 1" profile was designed to capture species that dissociated at a significantly lower temperature than the mercuric halides. The "oven 2 " profile, which began with a much steeper initial ramp from $100{ }^{\circ} \mathrm{C}$ to $170{ }^{\circ} \mathrm{C}$ and then with smaller increments to $250{ }^{\circ} \mathrm{C}$, was designed to try and distinguish between compounds with similar decomposition temperatures in the $170-250{ }^{\circ} \mathrm{C}$ range. Throughout the initial flushing and the heating cycle the gas that left the denuder passed through a fluorescence cell and the concentration of GEM was monitored by single photon LIF. After the heating cycle was complete the LIF signal was calibrated by injecting a known amount of GEM into the gas flow through a septum as described below.

\subsection{GEM Detection}

GEM was detected by single photon, resonance LIF using excitation of the $6^{3} \mathrm{P}_{1}-6{ }^{1} \mathrm{~S}_{0}$ transition at $253.7 \mathrm{~nm}$. A frequency doubled dye laser pumped by the third harmonic of a Nd-Yag laser was used to generate the excitation beam. Resonance fluorescence was observed using a Hamamatsu 1P28 photomultiplier tube with a $253 \mathrm{~nm}$ filter. In this approach the detection PMT detects both LIF and laser scatter and thus sensitivity is limited by the ratio of intensity of the LIF signal to the laser scatter. Since the $6^{3} \mathrm{P}_{1}$ level is efficiently quenched by both $\mathrm{O}_{2}$ and $\mathrm{N}_{2}$ the thermal analysis was performed in 
He buffer gas to achieve good detection sensitivity. The PTD profiles of all the samples collected during the Crist campaign used uncoated tubular denuders and the analysis used single photon LIF.

\subsection{Calibration of Absolute $\mathrm{Hg}^{\circ}$ Concentration}

The LIF signal was converted into an absolute $\mathrm{Hg}^{\circ}$ concentration by injecting known amounts of GEM into the detection cell through a septum. A saturated calibration gas was obtained by taking a sample of elemental mercury and allowing it to equilibrate at $6{ }^{\circ} \mathrm{C}$ for over $24 \mathrm{~h}$ before initial use. The elemental mercury was kept in a Pyrex vial capped with a septum in Ar bath gas. The transfer syringe was at room temperature and the saturated gas was withdrawn from the vial and directly injected slightly upstream of the fluorescence cell. The GEM concentration was calculated assuming saturation, correcting for the temperature difference between the syringe and the vial, and using the temperature dependence of the vapor pressure given by the Dumarey equation [20].

\section{7. $\mathrm{HgCl}_{2}$ Calibration Profiles}

After the completion of the sampling campaign at Plant Crist, thermal dissociation profiles of $\mathrm{HgCl}_{2}$ were measured for comparison with stack and plume samples. Samples were obtained by flowing $\mathrm{N}_{2}$ over powdered $\mathrm{HgCl}_{2}$ and passing the gas mixture through denuder tubes that were then analyzed using the "oven 1" or "oven 2" cycles. Calibration profiles from samples deposited at $\mathrm{N}_{2}$ flows of $520 \mathrm{sccm}$ and $135 \mathrm{sccm}$ were measured although there were large fluctuations in the deposited amounts of $\mathrm{HgCl}_{2}$ presumably as a result of fluctuating gas phase concentrations during sampling and variations in denuder collection efficiency. Six PTD profiles were measured using samples deposited at $135 \mathrm{sccm}$ and two PTD profiles at $520 \mathrm{sccm}$ deposition flow using the "oven 1" thermal ramp sequence. A single "oven 2" profile was measured, using a sample deposition flow of $520 \mathrm{sccm}$.

\subsection{Characterization of the Oven Temperature Distribution}

After the completion of the Plant Crist campaign and the laboratory $\mathrm{HgCl}_{2}$ calibration experiments the temperature distribution along a denuder tube was measured by attaching thermocouples at the ends and center of the inside of a tube and at the center on the outside of the tube. With the oven controller reading $190{ }^{\circ} \mathrm{C}$ the temperature at the center of the denuder was $212^{\circ} \mathrm{C}$ on the outside and $204{ }^{\circ} \mathrm{C}$ on the inside. The active heating section of the oven was $30 \mathrm{~cm}$ long and the temperature differential over the central $18 \mathrm{~cm}$ section was $30^{\circ} \mathrm{C}$ with a maximum at the center, a drop of $10{ }^{\circ} \mathrm{C}$ at $9 \mathrm{~cm}$ downstream, i.e., in the direction of gas flow, and a drop of $30^{\circ} \mathrm{C}$ at $9 \mathrm{~cm}$ upstream at the point where cool gas is entering. The differential then increased considerably and was $30{ }^{\circ} \mathrm{C}$ cooler $12.5 \mathrm{~cm}$ upstream and $50{ }^{\circ} \mathrm{C}$ cooler at the $12.5 \mathrm{~cm}$ downstream point. The ability of the oven controller to produce reproducible temperature ramps was limited with the temperature typically overshooting the set point.

\section{Conclusions}

Measurements of the chemical speciation of RGM represent a significant analytical challenge. Lack of information on the chemical speciation is perhaps the single biggest obstacle to developing 
a detailed understanding of the chemical cycling of mercury in the atmosphere. A "proof of concept" experiment as a component of a major field campaign was conducted to test the use of PTD to chemically speciate RGM in a working combustion environment. Thermal dissociation profiles for RGM were obtained in both stack and in-plume samples that suggest that it is possible to track a specific chemical form of RGM from the stack and follow its evolution in the stack plume. In contrast to the recently published work of Deeds et al. [4], comparison of the measured plume RGM with the amount calculated from in-stack measurements and the measured plume dilution suggest that the stack and plume RGM concentrations are consistent with dilution. The PTD profiles of the stack and plume samples are consistent with $\mathrm{HgCl}_{2}$ being the chemical form of the sampled RGM. It is also possible that the RGM consists of some other oxidized mercury species with a similar decomposition temperature. An example would be $\mathrm{HgBr}_{2}$, but the absence of a significant amount of bromine in the feed coal makes this unlikely. Comparison with literature PTD profiles of reference mercury compounds suggests no other likely candidates for the speciation of RGM.

\section{Acknowledgments}

We wish to acknowledge the assistance of many of the other participants in the Plant Crist campaign for performing measurements, providing logistical support and releasing results prior to publication. This work was supported by the Electric Power Research Institute.

\section{Author Contributions}

Anthony Hynes, Cheryl Tatum Ernest and Dieter Bauer wrote the manuscript and performed much of the data analysis. Cheryl Tatum Ernest and Dieter Bauer performed the field experiments. Arnout Ter Schure performed the analysis of trace gas dilutions. Anthony Hynes, Cheryl Tatum Ernest, Dieter Bauer and Arnout Ter Schure were involved in the planning and preparation for the field deployment. Deanna Donohoue performed preliminary experiments and provided scientific insight and editing.

\section{Conflicts of Interest}

The authors declare no conflict of interest.

\section{References}

1. Edgerton, E.S.; Hartsell, B.E.; Jansen, J.J. Mercury speciation in coal-fired power plant plumes observed at three surface sites in the Southeastern U.S. Environ. Sci. Technol. 2006, 40, 4563-4570.

2. EPRI. An Assessment of Mercury Emissions from U.S. Coal-Fired Power Plants; EPRI Report No. 1000608; Electric Power Research Institute: Palo Alto, CA, USA, 2000.

3. Lohman, K.; Seigneur, C.; Edgerton, E.S.; Jansen, J.J. Modeling mercury in power plant plumes. Environ. Sci. Technol. 2006, 40, 3848-3854. 
4. Deeds, D.A.; Banic, C.M.; Lu, J.; Daggupaty, S. Mercury speciation in a coal-fired power plant plume: An aircraft-based study of emissions from the 3640 MW Nanticoke Generating Station, ON, Canada. J. Geophys. Res.: Atmos. 2013, 118, 4919-4935.

5. Laudal, D.; Seigneur, C. Mercury Reactions in Power Plant Plumes: Pleasant Prairie Experiment and Compliance Scenario Assessment; Technical Report, Report No. 1010142; Electric Power Research Institute: Palo Alto, CA, USA, 2006.

6. Landis, M.; Ryan, J.; Oswald, E.; Jansen, J.; Monroe, L.; Walters, J.; Levin, L.; Ter Schure, A.; Laudal, D.; Edgerton, E. Plant crist mercury plume study. In Proceedings of Air Quality VII Conference, Arlington, VA, USA, 26-29 October 2009.

7. Schofield, K. Fuel-mercury combustion emissions: An important heterogeneous mechanism and an overall review of its implications. Environ. Sci. Technol. 2008, 42, 9014-9030.

8. Galbreath, K.C.; Zygarlicke, C.J. Mercury speciation in coal combustion and gasification flue gases. Environ. Sci. Technol. 1996, 30, 2421-2426.

9. Donohoue, D.A. Kinetic Studies of the Oxidation Pathways of Gaseous Elemental Mercury. Ph.D. Thesis, University of Miami, Miami, FL, USA, 2008.

10. Biester, H.; Scholz, C. Determination of mercury binding forms in contaminated soils: Mercury pyrolysis versus sequential extractions. Environ. Sci. Technol. 1997, 31, 233-239.

11. Feng, X.; Lu, J.; Gregoire, D.C.; Hao, Y.; Banic, C.M.; Schroeder, W.H. Analysis of inorganic mercury species associated with airborne particulate matter/aerosols: Method development. Anal. Bioanal. Chem. 2004, 380, 683-689.

12. Lopez-Anton, M.A.; Yang, Y.; Ron, P.; Maroto-Valer, M.M. Analysis of mercury species present during coal combustion by thermal desorption. Fuel 2010, 89, 629-634.

13. Wu, S.; Uddin, M.A.; Nagano, S.; Ozaki, M.; Sasaoka, E. Fundamental study on decomposition characteristics of mercury compounds over solid powder by temperature-programmed decomposition desorption mass spectrometry. Energy Fuels 2011, 25, 144-153.

14. Gormley, P.G.; Kennedy, M. Diffusion from a stream flowing through a cylindrical tube. Proc. R. Irish Acad. Sect. A 1949, 52, 163-169.

15. Schwarzenbach, R.P.; Gschwend, P.M.; Imboden, D.M. Environmental Organic Chemistry; John Wiley \& Sons, Inc.: New York, NY, USA, 1993.

16. Goldfinger, P.; Jeunehomme, M. Mass spectrometric and Knudsen cell vaporization studies of 2B-6B compounds. Trans. Faraday Soc. 1963, 59, 2851-2867.

17. Shepler, B.C.; Peterson, K.A. Mercury monoxide: A systematic investigation of its ground electronic state. J. Phys. Chem. A 2003, 107, 1783-1787.

18. Hynes, A.J.; Donohoue, D.L.; Goodsite, M.E.; Hedgecock, I.M. Our current understanding of major chemical and physical processes affecting mercury dynamics in the atmosphere and at the air-water/terrestrial interfaces. In Mercury Fate and Transport in the Global Atmosphere: Emissions, Measurements and Models; Pirrone, N., Mason, R.P., Eds.; Springer: Berlin, Germany, pp. 427-457.

19. Landis, M.S.; Stevens, R.K.; Schaedlich, F.; Prestbo, E. Development and characterization of an annular denuder methodology for the measurement of divalent inorganic reactive gaseous mercury in ambient air. Environ. Sci. Technol. 2002, 36, 3000-3009. 
20. Dumarey, R.; Brown, R.J.C.; Corns, W.T.; Brown, A.S.; Stockwell, P.B. Elemental mercury vapour in air: The origins and validation of the "Dumarey equation" describing the mass concentration at saturation. Accredit. Qual. Assur. 2010, 15, 409-414.

(C) 2014 by the authors; licensee MDPI, Basel, Switzerland. This article is an open access article distributed under the terms and conditions of the Creative Commons Attribution license (http://creativecommons.org/licenses/by/3.0/). 